\title{
Exigência de Lisina para Frangos de Corte Machos no Período de 22 a 42 Dias de Idade, Mantidos em Ambiente Quente $\left(26^{\circ} \mathrm{C}\right)^{1}$
}

\author{
Aurélio Ferreira Borges ${ }^{2}$, Rita Flávia Miranda de Oliveira ${ }^{3}$, Juarez Lopes Donzele ${ }^{3}$, \\ Uislei Antonio Dias Orlando ${ }^{4}$, Rony Antonio Ferreira ${ }^{4}$, Edilson Paes Saraiva ${ }^{4}$
}

RESUMO - Utilizaram-se 240 frangos de corte machos, Avian Farms, com peso médio de 541 $\pm 3,61$ g, no período de 22 a 42 dias de idade, mantidos em ambiente de temperatura alta, para se determinar a exigência de lisina. O delineamento experimental utilizado foi o inteiramente casualizado, com cinco tratamentos $(0,88 ; 0,94 ; 1,00 ; 1,06 ;$ e $1,12 \%$ de lisina total $)$, seis repetições e oito aves por repetição. Durante o período experimental, a temperatura manteve-se em $25,6 \pm 0,24^{\circ} \mathrm{C}$; a umidade relativa, em $68,4 \pm 6,30 \%$; a temperatura de globo negro, em 25,7 $\pm 0,25^{\circ} \mathrm{C}$; e o Índice de Temperatura de Globo e Umidade (ITGU), em 74 $\pm 0,6$. O fornecimento de ração e água foi à vontade. Os níveis de lisina da ração influenciaram o ganho de peso e a conversão alimentar, que aumentaram e melhoraram até os níveis de 1,05 e 1,03\%, respectivamente. O consumo de ração não foi influenciado pelos níveis de lisina da ração. Quanto à composição da carcaça, observou-se que os tratamentos influenciaram de forma quadrática a taxa de deposição de proteína, que aumentou até o nível de $1,05 \%$ de lisina. Os tratamentos influenciaram o peso absoluto da carcaça, peito com osso, perna, sobrecoxa e gordura abdominal e o peso relativo do peito com osso e da gordura abdominal. Concluiu-se que frangos de corte, no período de 22 a 42 dias de idade, submetidos à temperatura ambiente de $25,6^{\circ} \mathrm{C}$, exigem $1,05 \%$ de lisina total para máximo desempenho e deposição de proteína na carcaça.

Palavras-chave: frangos de corte, fase crescimento, lisina, ambiente térmico

\section{Lysine Requirement of Male Broilers from 22 to 42 Days of Age Kept under Hot Environment $\left(\mathbf{2 6}^{\circ} \mathrm{C}\right)$}

\begin{abstract}
Two hundred and forty male broilers, Avian Farms with average weight of $541 \pm 3.61 \mathrm{~g}$ from 22 to 42 days of age, kept under environment of high temperature were used to determining the lysine requirement. A completely randomized design, with five treatments $(0.88,0.94,1.00,1.06$, and $1.12 \%$ of total lysine level $)$, six replicates and eight broilers per replicate, was used. During the experimental period, the air temperature was maintained in $25.6 \pm 0.24^{\circ} \mathrm{C}$, the relative humidity in $68.4 \pm 6.30^{\circ} \mathrm{C}$, the black globe temperature in $25.7 \pm 0.25^{\circ} \mathrm{C}$ and the black globe humidity index (BGHI) in $74 \pm 0.6$. Feed and water were ad libitum fed to broilers. The dietary lysine levels affected the weight gain, that increased, and the feed:gain ratio, that increased and improved until the levels of 1.05 and $1.03 \%$, respectively. Feed intake was not affected by the dietary lysine levels. For the carcass composition, it was observed that the treatments quadraticly affected the protein deposition rate, that increased up to $1.05 \%$ of lysine. The absolute weight of carcass, breast without bone, legs, thigh and of abdominal fat, as well as the relative weight of breast with bone and of abdominal fat, were affected by the treatments. It was concluded that male broilers from 22 to 42 days of age kept under $25.6^{\circ} \mathrm{C}$ of environmental temperature require $1.05 \%$ of total lysine in the diet for maximum performance and protein deposition in the carcass.
\end{abstract}

Key Words: broiler, growing phase, lysine, thermal environment

\section{Introdução}

As aves são animais homeotérmicos que mantêm a sua temperatura corporal por meio de alterações fisiológicas e comportamentais.

$\mathrm{Na}$ ocorrência de qualquer alteração do ambiente, fora da faixa de conforto térmico, os animais homeotérmicos necessitam de ajustes de natureza comportamental, física ou fisiológica, como tentativa de se adaptarem à nova condição ambiental. Oliveira
Neto (1999) relatou que a faixa de termoneutralidade para frangos de corte está situada entre 18 e $15^{\circ} \mathrm{C}$. Entre estes ajustes destaca-se o consumo de ração, que é reduzido quando a temperatura ambiental aumenta, ocasionando, conseqüentemente, diminuição na taxa de crescimento das aves e piora na conversão alimentar (Baziz et al., 1996). Entretanto, o efeito da temperatura sobre o metabolismo é mais complexo do que o freqüentemente relatado. De acordo com Mendes et al. (1997), a combinação de alta tempera-

\footnotetext{
${ }_{1}^{1}$ Parte da tese de Mestrado do primeiro autor - Projeto Financiado pela FAPEMIG.

2 Professor da Escola Agrotécnica Federal de Colorado do Oeste-RO.

3 Professor do DZO/UFV. E.mail: flavia@mail.ufv.br; donzele@mail.ufv.br

${ }^{4}$ Estudante de Doutorado do DZO/UFV. E.mail: uislei@mailcity.com
} 
tura ambiente com elevado nível de proteína reduz a taxa de crescimento e a produção de carne de peito de frangos de corte de linhagem comercial de rápido crescimento.

A alta temperatura promove ainda a redução no peso dos órgãos de aves (Oliveira Neto et al., 1998) e suínos (Oliveira et al., 1997), visando diminuir a taxa metabólica dos animais, com conseqüente redução na produção de calor. Trabalhos realizados por Rostagno (1997) mostraram que o nível protéico das rações de frangos de corte, criados em condições de alta temperatura, pode ser reduzido pela suplementação de aminoácidos sintéticos sem modificar o desempenho.

Assim, considerando as diferentes respostas associadas ao efeito da alta temperatura, fica evidente que a exigência das aves deve variar não somente em razão da linhagem, mas também em conseqüência do ambiente térmico a que esses animais são submetidos nos diferentes períodos.

Este trabalho foi conduzido com o objetivo de determinar a exigência de lisina para frangos de corte machos, no período de 22 a 42 dias de idade, mantidos em ambiente de alta temperatura.

\section{Material e Métodos}

O experimento foi conduzido nas câmaras climáticas do Laboratório de Bioclimatologia Animal do Departamento de Zootecnia, do Centro de Ciências Agrárias da Universidade Federal de Viçosa, Viçosa, MG.

Foram utilizados 240 frangos machos, da linhagem Avian Farms, com peso inicial médio de $541 \pm$ 3,61 g, vacinados contra as doenças de Marek e Bouba aviária. As aves permaneceram no experimento do $22^{\circ}$ ao $42^{\circ}$ dia de idade, mantidos em ambiente com alta temperatura $\left(25,6^{\circ} \mathrm{C}\right)$. O delineamento experimental utilizado foi o inteiramente casualizado com cinco tratamentos (níveis de lisina), seis repetições e oito aves por repetição.

As rações experimentais (Tabela 1), isoprotéicas e isoenergéticas, à base de milho, farelo de soja e glúten de milho, foram formuladas para atender as exigências nutricionais das aves em proteína, energia, cálcio, fósforo e aminoácidos, segundo Rostagno et al. (1996), exceto com relação à lisina. As rações foram suplementadas com 0,000; 0,076; 0,153; 0,230; e 0,306\% de L-lisina $\mathrm{HCl} 78,4 \%$, resultando em rações com 0,$88 ; 0,94 ; 1,00 ; 1,06$; e $1,12 \%$ de lisina total.

Durante o período inicial ( 1 a 21 dias de idade), as aves foram criadas em galpão convencional sob manejo e alimentação tradicionais descritos por Gomes et al. (1996). Completados os 22 dias de idade, os frangos foram pesados e transferidos para as câmaras climáticas, quando teve início o período experimental. Os animais permaneceram no experimento até os 42 dias de idade.

As aves foram alojadas em bateria metálica com 12 compartimentos, com piso telado de área igual a $0,72 \mathrm{~m}^{2} /$ compartimento, dotadas de comedouros e bebedouros tipo calha, constituindo-se cada compartimento uma unidade experimental.

O monitoramento de temperatura e umidade de cada sala foi feito por meio de termômetros de máxima e mínima, de bulbo seco e de bulbo úmido e de globo negro, colocados à altura intermediária em relação ao compartimento central da bateria. As temperaturas foram registradas diariamente em dois horários (8 e $18 \mathrm{~h}$ ), durante todo o período experimental.

$\mathrm{O}$ ambiente térmico foi expresso em termos de Índice de Temperatura de Globo e Umidade (ITGU), proposto por Buffington et al. (1981), e calculado utilizando-se a seguinte equação:

$$
\text { ITGU = Tgn + 0,36 Tpo - 330,08 }
$$

em que: Tgn é temperatura de globo negro, em oK, e Tpo, temperatura de ponto de orvalho, em oK.

As rações e a água foram fornecidas à vontade, sendo a água trocada duas vezes ao dia para evitar aquecimento.

O programa de luz adotado durante todo o período experimental foi o contínuo ( 24 horas de luz artificial), fazendo-se uso de duas lâmpadas fluorescentes de $25 \mathrm{~W}$ cada, por sala.

As variáveis estudadas foram: consumo de ração, ganho de peso, conversão alimentar, consumo de lisina total, rendimento de carcaça, deposição de proteína e pesos absoluto e relativo de cortes nobres (peito, coxa, sobrecoxa e pernas).

O cálculo do consumo de ração no período experimental foi obtido pela diferença entre a quantidade de ração fornecida e as perdas e sobras de rações experimentais, pesadas no início e no final do experimento.

O ganho de peso das aves foi obtido pela diferença de pesagem dos animais no final e no início do período experimental.

A partir dos dados de consumo de ração e de ganho de peso, calculou-se a conversão alimentar dos animais no período de 22 a 42 dias de idade.

Ao final do experimento, após 12 horas de jejum,

R. Bras. Zootec., v.31, n.5, p.1993-2001, 2002 
Tabela 1 - Composição percentual calculada das rações experimentais

Table 1 - Calculated composition of the experimental diets (\%)

\begin{tabular}{|c|c|c|c|c|c|}
\hline \multirow[t]{2}{*}{$\begin{array}{l}\text { Ingredientes } \\
\text { Ingredients }\end{array}$} & \multicolumn{5}{|c|}{$\begin{array}{c}\text { Nível de lisina total (\%) } \\
\text { Total lysine level }(\%)\end{array}$} \\
\hline & 0,88 & 0,94 & 1,00 & 1,06 & 1,12 \\
\hline $\operatorname{Milho}($ Corn $)(7,98 \%$ PB $)$ & 65,500 & 65,500 & 65,500 & 65,500 & 65,500 \\
\hline Farelo de soja (Soybean meal) $(45,61 \%$ PB) & 21,870 & 21,870 & 21,870 & 21,870 & 21,870 \\
\hline Glúten de milho (Corn gluten meal) $(60,38 \% \mathrm{~PB})$ & 7,122 & 7,122 & 7,122 & 7,122 & 7,122 \\
\hline Fosfato bicálcico (Dicalcium phosphate) & 1,524 & 1,524 & 1,524 & 1,524 & 1,524 \\
\hline Calcário(Limestone) & 1,228 & 1,228 & 1,228 & 1,228 & 1,228 \\
\hline Óleo de soja (Soybean oil) & 1,200 & 1,200 & 1,200 & 1,200 & 1,200 \\
\hline Sal comum $($ Salt $)$ & 0,415 & 0,415 & 0,415 & 0,415 & 0,415 \\
\hline Mistura mineral (Mineral mix $)^{1}$ & 0,050 & 0,050 & 0,050 & 0,050 & 0,050 \\
\hline Mistura vitamínica (Vitamin mix) ${ }^{2}$ & 0,100 & 0,100 & 0,100 & 0,100 & 0,100 \\
\hline BHT & 0,010 & 0,010 & 0,010 & 0,010 & 0,010 \\
\hline Cocxistac ${ }^{*}$ & 0,050 & 0,050 & 0,050 & 0,050 & 0,050 \\
\hline Cloreto de colina (Choline chloride) & 0,125 & 0,125 & 0,125 & 0,125 & 0,125 \\
\hline Virginiamicina(Virginiamicin) & 0,055 & 0,055 & 0,055 & 0,055 & 0,055 \\
\hline Caulin & 0,596 & 0,520 & 0,443 & 0,366 & 0,290 \\
\hline $\mathrm{L}$ - Lisina $\mathrm{HCl}($ L-Lysine $H C L)(78,4 \%)$ & 0,000 & 0,076 & 0,153 & 0,230 & 0,306 \\
\hline DL - Metionina (DL-Methionine) $(99 \%)$ & 0,153 & 0,153 & 0,153 & 0,153 & 0,153 \\
\hline Triptofano (Tryptophan) (99\%) & 0,005 & 0,005 & 0,005 & 0,005 & 0,005 \\
\hline \multicolumn{6}{|l|}{ Composição calculada (Calculated composition) } \\
\hline Proteína bruta (Crude protein) $(\%)$ & 19,570 & 19,570 & 19,570 & 19,570 & 19,570 \\
\hline Energi metabolizável (Metabolizable energy) (kcal/kg) & 3.100 & 3.100 & 3.100 & 3.100 & 3.100 \\
\hline Cálcio $($ Calcium $)(\%)$ & 0,918 & 0,918 & 0,918 & 0,918 & 0,918 \\
\hline Fósforo disponível (Available phosphorus) (\%) & 0,389 & 0,389 & 0,389 & 0,389 & 0,389 \\
\hline Sódio (Sodium) $(\%)$ & 0,200 & 0,200 & 0,200 & 0,200 & 0,200 \\
\hline Lisina total (Total lysine) & 0,880 & 0,940 & 1,000 & 1,060 & 1,120 \\
\hline Lisina digestível (Digestible lysine) $(\%)^{3}$ & 0,780 & 0,840 & 0,900 & 0,960 & 1,020 \\
\hline Triptofano digestível (Digestible tryptophan) $(\%)^{3}$ & 0,150 & 0,150 & 0,150 & 0,150 & 0,150 \\
\hline Valina digestível (Digestible valine) $(\%)^{3}$ & 0,814 & 0,814 & 0,814 & 0,814 & 0,814 \\
\hline Treonina digestível (Digestible threonine) $(\%)^{3}$ & 0,632 & 0,632 & 0,632 & 0,632 & 0,632 \\
\hline Metionina + cistina digestível $($ Digestible meth + cys) & )$^{3} 0,515$ & 0,515 & 0,515 & 0,515 & 0,515 \\
\hline
\end{tabular}

as aves foram pesadas, sendo, posteriormente, escolhidas quatro de cada repetição, considerando-se o peso médio da unidade experimental $( \pm 5 \%)$, para serem abatidas. Após as aves serem sangradas e depenadas, as carcaças evisceradas foram pesadas. Posteriormente, a gordura abdominal foi retirada e pesada. As duas carcaças inteiras (incluindo pés e cabeça) de cada repetição foram moídas, uma a uma, durante 15 minutos, em "cutter" comercial de $30 \mathrm{HP}$ e $1.775 \mathrm{rpm}$, sendo, após homogeneização, coletada uma amostra. As amostras das carcaças, em razão do seu alto teor de gordura, foram pré-secas em estufa de ventilação forçada a $\pm 60^{\circ} \mathrm{C}$, durante 72 horas, e pré-desengorduradas pelo método a quente em aparelho extrator do tipo "Soxhlet", durante quatro horas. Após esta etapa, as amostras foram moídas e acondicionadas em vidros para análises posteriores.

As análises de proteína bruta das amostras foram realizadas no Laboratório de Nutrição Animal do Departamento de Zootecnia da UFV, conforme metodologia descrita por Silva (1992).

Um grupo adicional de 15 aves com 21 dias de idade foi abatido para determinação da composição corporal no início do experimento. A deposição de proteína na carcaça foi calculada pela diferença entre os valores de composição da carcaça dos frangos de corte com 22 e 42 dias de idade.

As duas carcaças restantes em cada repetição (totalizando 12 carcaças por tratamento) foram utilizadas para obtenção dos cortes, em que se avaliaram 
o peso absoluto (g) e o rendimento (\%) das carcaças inteiras (com pés e cabeça), da perna, da coxa, da sobrecoxa, do peito, das penas e da gordura abdominal.

O rendimento da carcaça foi obtido da razão entre o peso da carcaça limpa e eviscerada (com pés e cabeça) e o peso vivo após jejum. Já o rendimento de cortes nobres foi determinado considerando-se o peso da carcaça eviscerada e sem pena.

As análises estatísticas das características avaliadas foram realizadas utilizando-se o Sistema para Análises Estatísticas - SAEG (1997). As estimativas de exigência de lisina total foram estabelecidas por meio de modelos de regressão linear e, ou, quadrático e pelo Linear Response Plateau - LRP, conforme o melhor ajuste.

\section{Resultados e Discussão}

Na Tabela 2 são apresentados os valores médios das condições ambientais no interior das câmaras climáticas, obtidos durante o período experimental. Considerando-se que o manual da linhagem Avian Farms recomenda para a categoria de 22 a 42 dias de idade a temperatura em torno de $22,5^{\circ} \mathrm{C}$ e a umidade em torno de $70 \%$ e, ainda, que, segundo Campos (1985), o limite da temperatura de termoneutralidade está por volta de $25^{\circ} \mathrm{C}$, pode-se inferir que as condições em que o experimento foi conduzido caracterizaram ambiente moderadamente quente. Oliveira Neto (1999) caracterizou como ambiente de conforto, para esta categoria de animais, aquele que tivesse ITGU em torno de 72 e como de estresse por calor, um ITGU de 84.

Na Tabela 3 são apresentados os resultados de desempenho (ganho de peso, consumo de ração e conversão alimentar), de consumo de lisina total e das taxas de deposição de gordura e proteína na carcaça de frangos de corte, no período de 22 a 42 dias de idade, recebendo rações com diferentes níveis de lisina e mantidos em alta temperatura $\left(25,6^{\circ} \mathrm{C}\right)$. Observou-se efeito $(\mathrm{P}<0,09)$ dos níveis de lisina da ração sobre o ganho de peso (GP) das aves, que aumentou de forma quadrática até o nível de 1,05\% (Figura 1), associado a um consumo de $25 \mathrm{~g}$ de lisina total. Este resultado foi maior que aqueles de 0,92 e $0,98 \%$ de lisina total obtidos por Barboza (1998) para frangos de corte machos das marcas Hubbard e Ross, respectivamente, de 22 a 40 dias de idade, e de 0,85 e $1,00 \%$ de lisina total obtidos por Scheuermann et al. (1993) e Barboza (1998), também
Tabela 2 - Condições ambientais médias observadas durante o período experimental, nas câmaras climáticas alojando frangos de corte, de 22 a 42 dias de idade

Table 2 - Average environmental conditions observed during the experimental period in the climatic chambers maintaining broilers from 22 to 42 days of age

\begin{tabular}{lc}
\hline $\begin{array}{l}\text { Variáveis } \\
\text { Variables }\end{array}$ & $\begin{array}{c}\text { Valores } \\
\text { Values }\end{array}$ \\
\hline $\begin{array}{l}\text { Temperatura do ar média }\left({ }^{\circ} \mathrm{C}\right) \\
\text { Average air temperature }\end{array}$ & $25,6 \pm 0,24$ \\
$\begin{array}{l}\text { Umidade relativa média }(\%) \\
\text { Average relative humidity }\end{array}$ & $68,4 \pm 6,30$ \\
$\begin{array}{l}\text { Temperatura de globo negro média }\left({ }^{\circ} \mathrm{C}\right) \\
\text { Average black globe temperature }\end{array}$ & $25,7 \pm 0,25$ \\
$\begin{array}{l}\text { Indice de temperatura de globo e } \\
\text { umidade (ITGU) }\end{array}$ & $73,7 \pm 0,60$ \\
Black globe humidity index & \\
\hline
\end{tabular}

para ganho de peso de frangos de corte machos no período de 21 a 42 e 22 a 40 dias de idade, respectivamente. Por outro lado, Conhalato (1998) obteve melhor resultado de ganho de peso para aves no período de 22 a 42 dias criadas nos períodos quentes do ano (temperatura média acima de $26^{\circ} \mathrm{C}$ ) com nível de lisina total $(1,20 \%)$ acima do encontrado neste trabalho. De forma contrária, Mendes et al. (1997) não constataram influência do nível de lisina sobre o ganho de peso de frangos na fase de 21 a 42 dias, submetidos à alta temperatura ambiente $\left(25,5\right.$ a $\left.33^{\circ} \mathrm{C}\right)$.

As diferenças de resultados entre os trabalhos citados podem estar associadas à genética dos animais, além da diferença de temperatura ambiente em que os mesmos foram conduzidos. Segundo Cahaner et al. (1995), as exigências nutricionais das aves são influenciadas pela temperatura ambiente e pela genética.

Não se constatou efeito dos níveis de lisina sobre o consumo de ração (CR) dos frangos. Resultados semelhantes foram obtidos por Resende et al. (1980), que, trabalhando com frangos de corte submetidos à alta temperatura $\left(29^{\circ} \mathrm{C}\right)$ durante a fase de 29 a 42 dias, não verificaram efeito dos níveis de lisina sobre o consumo de ração. Posteriormente, Mendes et al. (1997), trabalhando com frangos de 21 a 42 dias mantidos em alta temperatura $\left(25,5\right.$ a $\left.33,3^{\circ} \mathrm{C}\right)$, também não verificaram efeito dos níveis de lisina sobre o consumo de ração.

Considerando que os animais, de maneira geral, quando expostos à alta temperatura, têm o consumo de ração reduzido para evitar aumento na produção de calor (Baziz et al., 1996), pode-se deduzir que nesta condição as aves teriam comprometida capaci-

\section{R. Bras. Zootec., v.31, n.5, p.1993-2001, 2002}


Tabela 3 - Desempenho, consumo de lisina total e taxa de deposição de proteína de frangos de corte, machos, no período de 22 a 42 dias de idade, recebendo rações com diferentes níveis de lisina, mantidos em alta temperatura

Table 3 - Performance, total lysine intake and protein deposition rate of male broilers from 22 at 42 days of age fed diets with different levels of lysine, under high temperature environment

\begin{tabular}{|c|c|c|c|c|c|c|}
\hline \multirow[t]{2}{*}{$\begin{array}{l}\text { Parâmetros } \\
\text { Parameters }\end{array}$} & \multicolumn{5}{|c|}{$\begin{array}{c}\text { Níveis de lisina }(\%) \\
\text { Lysine levels }\end{array}$} & \multirow[t]{2}{*}{$\mathrm{CV}(\%)$} \\
\hline & 0,88 & 0,94 & 1,00 & 1,06 & 1,12 & \\
\hline $\begin{array}{l}\text { Ganho de peso }(\mathrm{g})^{1} \\
\text { Weight gain }\end{array}$ & 1219 & 1265 & 1293 & 1315 & 1283 & 4,53 \\
\hline $\begin{array}{l}\text { Consumo de ração }(\mathrm{g}) \\
\text { Feed intake }\end{array}$ & 2371 & 2350 & 2369 & 2383 & 2390 & 4,62 \\
\hline $\begin{array}{l}\text { Conversão alimentar }{ }^{2} \\
\text { Feed:gain ratio }\end{array}$ & 1,94 & 1,86 & 1,83 & 1,81 & 1,86 & 2,76 \\
\hline $\begin{array}{l}\text { Consumo lisina total }(\mathrm{g})^{3} \\
\text { Total lysine intake } \\
\text { Taxa de deposição de proteína }{ }^{4}(\mathrm{~g})\end{array}$ & 21 & 22 & 24 & 25 & 27 & 4,81 \\
\hline Protein deposition rate & 164 & 166 & 177 & 180 & 173 & 3,46 \\
\hline
\end{tabular}

dade de ajustar o consumo, em razão da concentração dos nutrientes da ração.

Os níveis de lisina da ração influenciaram $(\mathrm{P}<0,01)$ de forma quadrática a conversão alimentar (CA), que melhorou até o nível de 1,03\% de lisina total (Figura 2), correspondendo a $0,93 \%$ de lisina digestível e a um consumo de lisina total estimado de $24,5 \mathrm{~g}$. Efeito quadrático do nível de lisina sobre a conversão alimentar de frangos, no período de 22 a 42 dias de idade, foi também constatado por Barboza (1998) e Conhalato (1998).

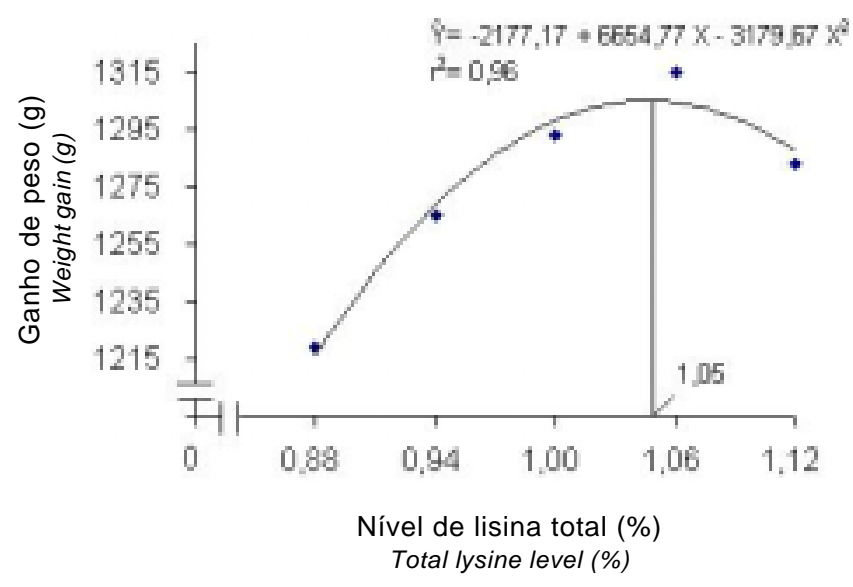

Figura 1 - Nível de lisina da ração e ganho de peso (g) de frangos de corte de 22 a 42 dias mantidos em ambiente de alta temperatura $\left(25,6^{\circ} \mathrm{C}\right)$.

Figure 1 - Dietary lysine level and weight gain $(\mathrm{g})$ of broilers from 22 to 42 days of age, under high environmental temperature $\left(25.6^{\circ} \mathrm{C}\right)$.

R. Bras. Zootec., v.31, n.5, p.1993-2001, 2002
O resultado obtido neste estudo também está coerente com os de Moran Jr. \& Bilgili (1990), que, trabalhando com frangos de 28 a 42 dias de idade, verificaram melhora linear na conversão alimentar, quando o nível de lisina aumentou de 0,85 a $1,05 \%$. Por outro lado, Mendes et al. (1997), trabalhando em ambiente de alta temperatura $\left(25\right.$ a $\left.33^{\circ} \mathrm{C}\right)$ com frangos de corte na fase de 21 a 42 dias, não verificaram efeito dos níveis de lisina da ração sobre a conversão alimentar.

O consumo de lisina total aumentou de forma

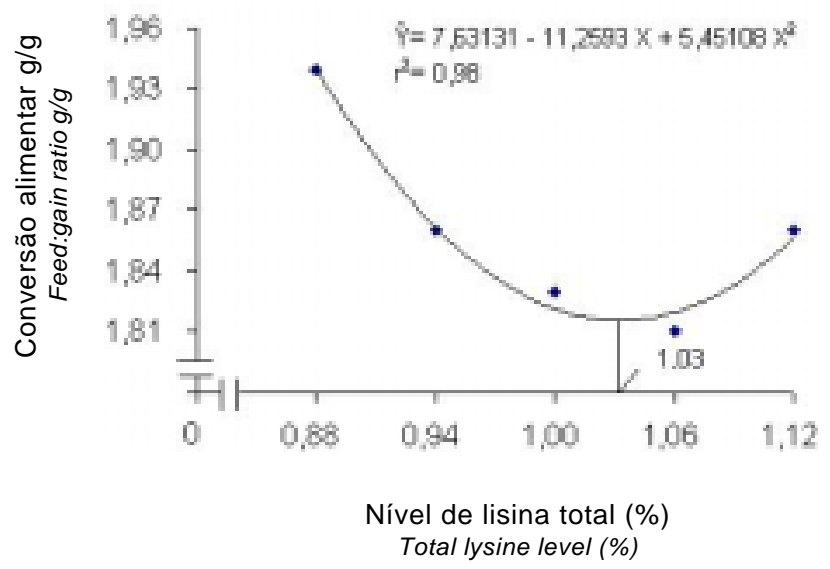

Figura 2 - Nível de lisina da ração e conversão alimentar $(\mathrm{g} / \mathrm{g})$ de frangos de corte de 22 a 42 dias mantidos em ambiente de alta temperatura $\left(25,6^{\circ} \mathrm{C}\right)$.

Figure 2 - Dietary lysine level and feed:gain ratio $(\mathrm{g} / \mathrm{g})$ of broilers from 22 to 42 days of age, under high environmental temperature $\left(25.6^{\circ} \mathrm{C}\right)$. 
linear $(\mathrm{P}<0,01)$, em razão da elevação do nível de lisina da ração, segundo a equação $\hat{Y}=-1,23113+24,9651$ lis $\left(r^{2}=0,99\right)$. Este resultado é justificado pelo fato de o consumo de ração não ter variado entre os tratamentos. Embora tenha havido aumento linear no consumo de lisina total, observou-se que o consumo de $25 \mathrm{~g}$ proporcionou o maior valor absoluto em ganho e deposição de proteína na carcaça.

Quanto à composição da carcaça, foi observado efeito $(\mathrm{P}<0,03)$ dos níveis de lisina total da ração sobre a taxa de deposição de proteína (TDP), que aumentou de forma quadrática até o nível de 1,05\% (Figura 3). Este resultado corrobora os obtidos por Summers et al. (1992) e Deschepper \& Groote (1995), que também verificaram alteração na composição química da carcaça de frangos aos 42 dias de idade, quando utilizaram rações com baixa proteína suplementada com aminoácidos essenciais, trabalhando em ambiente termoneutro.

De forma contrária, Conhalato (1998) não verificou efeito dos níveis de lisina sobre a composição química da carcaça de frangos aos 42 dias, quando trabalhou nos meses quentes do ano.

Considerando que a deposição de proteína, por agregar maior quantidade de água, é mais eficiente que a de gordura, o aumento na TDP na carcaça até o nível de $1,05 \%$ de lisina total justifica as melhoras observadas no GP e na CA dos frangos.

$\mathrm{Na}$ Tabela 4 são apresentados os resultados de rendimento em valores absolutos de carcaça, cortes nobres (peito, coxa e sobrecoxa) e gordura abdominal de frangos de corte de 22 a 42 dias.

Os níveis de lisina na ração influenciaram $(\mathrm{P}<0,03)$ o peso absoluto e o rendimento de carcaça (Figuras 4 e 5), que aumentaram de forma quadrática até os níveis de 1,01 e $0,96 \%$ de lisina, respectivamente. De forma contrária, Moran Jr. \& Bilgili (1990), Scheuermann et al. (1993), Kidd et al. (1997) e Conhalato (1998) não verificaram influência dos níveis de lisina sobre o rendimento de carcaça de frangos de corte, na fase de 21 a 42 dias, criados nos meses quentes do ano. Barboza (1998) também não verificou efeito dos níveis de lisina sobre o rendimento de carcaça de frangos de corte na fase de 22 a 40 dias, trabalhando em ambiente termoneutro.

Houve efeito quadrático dos níveis de lisina sobre o peso absoluto de carne de peito com osso $(\mathrm{P}<0,01)$, que aumentou até o nível de 1,06\% de lisina (Figura 6), e efeito linear $(\mathrm{P}<0,01)$ sobre o peso relativo de peito com osso, que se elevou, conforme a equação

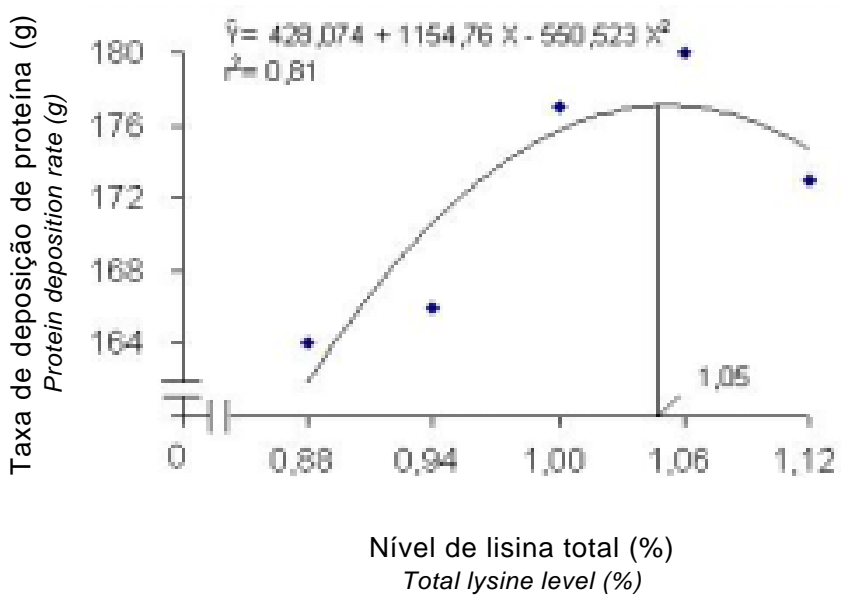

Figura 3 - Nível de lisina da ração e taxa de deposição de proteína ( $\mathrm{g}$ ) de frangos de corte de 22 a 42 dias mantidos em ambiente de alta temperatura $\left(25,6^{\circ} \mathrm{C}\right)$.

Figure 3 - Dietary lysine level and protein deposition rate $(g)$ of broilers from 22 to 42 days of age, under high environmental temperature $\left(25.6^{\circ} \mathrm{C}\right)$.

$\hat{\mathrm{Y}}=16,81124+10,6134$ lis $\left(\mathrm{r}^{2}=0,67\right)$.

Estes resultados corroboram os obtidos por Jackson (1989), Moran Jr. \& Bilgili (1990), Holsheimer \& Veerkamp (1992) e Han \& Baker (1994), que verificaram variação na produção de carne de peito, em razão do nível de lisina da ração. Hickling et al. (1989) e Barboza (1998) constataram incremento de $2,8 \%$ no rendimento de peito, com o aumento nos níveis de lisina de 0,95 a $1,15 \%$ e de 0,8 a $0,98 \%$, respectivamente.

Os resultados obtidos neste trabalho são coerentes, uma vez que, segundo Baker (1991), a lisina tem grande participação na composição da proteína muscular e, de acordo com Moran Jr. \& Bilgili (1990), o fornecimento de lisina em níveis adequados é fundamental para produção de carne de peito. Ainda, de acordo com Sibbald \& Wolynetz (1986), Bilgili et al. (1992) e Kidd et al. (1997), o requerimento de aminoácidos essenciais para máximo rendimento de carne de peito está acima do considerado adequado para máximo crescimento.

Os níveis de lisina influenciaram $(\mathrm{P}<0,07)$ de forma quadrática o peso absoluto de pernas, que aumentou até o nível de $1,06 \%$ de lisina total, segundo a equação $\hat{Y}=-497,899+1673,27$ lis $788,216 \operatorname{lis}^{2}\left(\mathrm{r}^{2}=0,80\right)$. Da mesma forma, Conhalato (1998) e Barboza (1998) não observaram efeito dos níveis de lisina sobre o rendimento de pernas de 
Tabela 4 - Pesos absoluto e relativo de carcaça, cortes nobres e gordura abdominal de frangos de corte aos 42 dias, mantidos em alta temperatura

Table 4 - Absolute and relative weights of carcass, prime cuts and abdominal fat of broilers at 42 days of age, under high environmental temperature

\begin{tabular}{|c|c|c|c|c|c|c|}
\hline \multirow[t]{2}{*}{$\begin{array}{l}\text { Parâmetros } \\
\text { Parameters }\end{array}$} & \multicolumn{5}{|c|}{$\begin{array}{c}\text { Níveis de lisina (\%) } \\
\text { Lysine levels }\end{array}$} & \multirow[t]{2}{*}{$\mathrm{CV}(\%)$} \\
\hline & 0,88 & 0,94 & 1,00 & 1,06 & 1,12 & \\
\hline & \multicolumn{5}{|c|}{$\begin{array}{l}\text { Peso absoluto }(\mathrm{g}) \\
\text { Absolute weight }\end{array}$} & \\
\hline $\begin{array}{l}\text { Peso após jejum } \\
\text { Weight afterfasting }\end{array}$ & 1720 & 1765 & 1794 & 1857 & 1789 & 5,24 \\
\hline $\begin{array}{l}\text { Carcaça }{ }^{1} \\
\text { Carcass }\end{array}$ & 1371 & 1412 & 1439 & 1474 & 1407 & 5,07 \\
\hline $\begin{array}{l}\text { Peito com osso } \\
\text { Breast with bone }\end{array}$ & 349 & 390 & 403 & 398 & 405 & 6,70 \\
\hline $\begin{array}{l}\text { Pernas }{ }^{3} \\
\text { Legs }\end{array}$ & 369 & 368 & 389 & 397 & 382 & 4,87 \\
\hline $\begin{array}{l}\text { Coxa } \\
\text { Drumstick }\end{array}$ & 183 & 184 & 188 & 194 & 187 & 4,93 \\
\hline $\begin{array}{l}\text { Sobrecoxa } \\
\text { Thigh }\end{array}$ & 186 & 183 & 202 & 202 & 193 & 6,38 \\
\hline $\begin{array}{l}\text { Gordura abdominal } \\
\text { Abdominal fat }\end{array}$ & 19 & 16 & 14 & 16 & 18 & 16,75 \\
\hline & & & $\begin{array}{l}\text { elativ } \\
\text { tive we }\end{array}$ & & & \\
\hline $\begin{array}{l}\text { Carcaça }^{1} \\
\text { Carcass }\end{array}$ & 79,7 & 80,0 & 80,2 & 79,4 & 78,7 & 1,48 \\
\hline $\begin{array}{l}\text { Peito com osso } \\
\text { Breast with bone }\end{array}$ & 25,5 & 27,6 & 27,8 & 27,3 & 28,8 & 3,26 \\
\hline $\begin{array}{l}\text { Pernas } \\
\text { Legs }\end{array}$ & 0,27 & 0,26 & 0,27 & 0,27 & 0,27 & 3,34 \\
\hline $\begin{array}{l}\text { Coxa } \\
\text { Drumstick }\end{array}$ & 13,3 & 13,2 & 13,0 & 13,0 & 13,2 & 3,58 \\
\hline $\begin{array}{l}\text { Sobrecoxa } \\
\text { Thigh }\end{array}$ & 13,8 & 13,1 & 14,1 & 13,7 & 13,7 & 4,65 \\
\hline $\begin{array}{l}\text { Gordura abdominal } \\
\text { Abdominal fat }\end{array}$ & 1,39 & 1,10 & 0,97 & 1,10 & 1,31 & 15,92 \\
\hline
\end{tabular}

1,2,3 Efeito quadrático $(P<0,03),(P<0,01)$ e $(P<0,07)$, respectivamente (Quadratic effect $(P<.03),(P<.01)$ and $(P<.07)$, respectively).

$4 \quad$ Efeito linear $(P<0,01)$ (Linear effect $[P<.01])$.

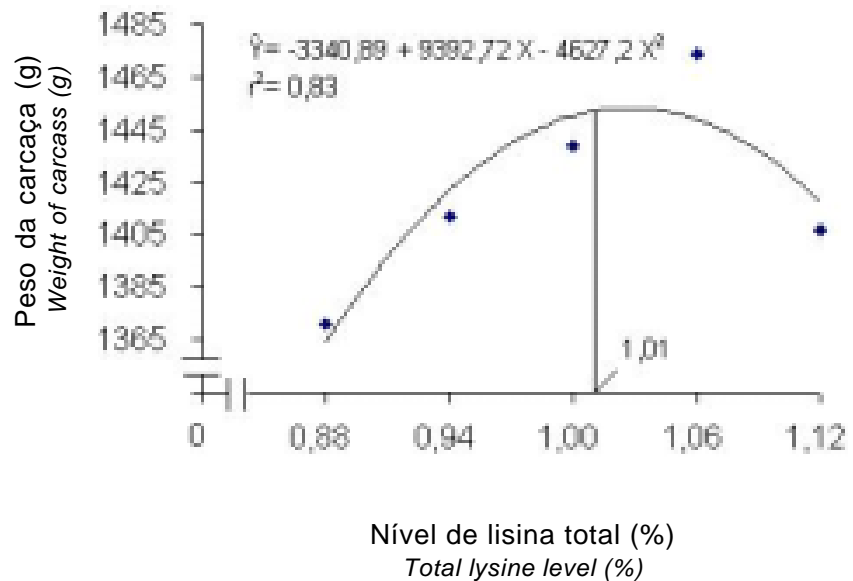

Figura 4 - Nível de lisina da ração e peso absoluto da carcaça $(\mathrm{g})$ de frangos de corte aos 42 dias mantidos em ambiente de alta temperatura $\left(25,6^{\circ} \mathrm{C}\right)$.

Figure 4 - Dietary lysine level diet and absolute weight of carcass $(g)$ of broilers at 42 days of age, under high environmental temperature $\left(25.6^{\circ} \mathrm{C}\right)$.

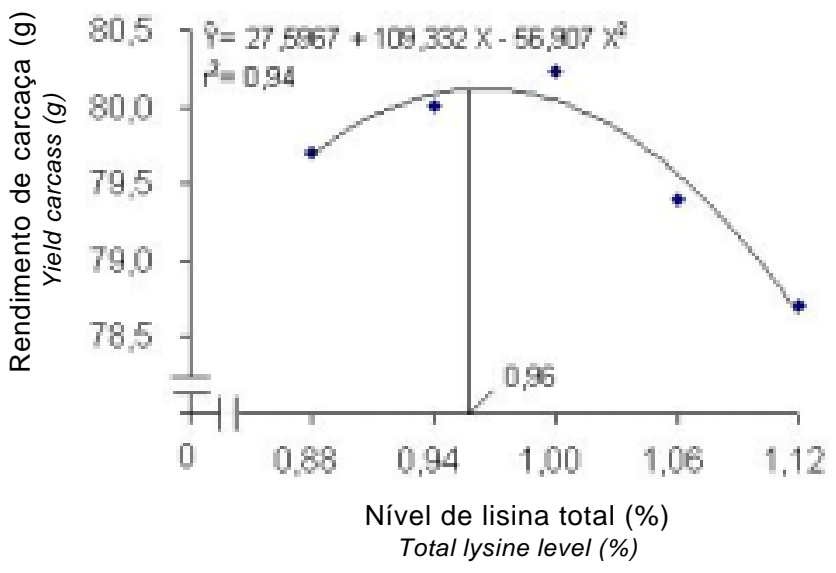

Figura 5 - Nível de lisina da ração e rendimento de carcaça (\%) de frangos de corte aos 42 dias mantidos em ambiente de alta temperatura $\left(25,6^{\circ} \mathrm{C}\right)$.

Figure 5 - Dietary lysine level and carcass yield (\%) of broilers at 42 days of age, under high environmental temperature $\left(25.6^{\circ} \mathrm{C}\right)$

R. Bras. Zootec., v.31, n.5, p.1993-2001, 2002 
frangos de corte de 22 a 42 dias e de 22 a 40 dias, respectivamente. Em contrapartida, Mendes et al. (1997) verificaram influência dos níveis crescentes de lisina sobre rendimento de pernas para frangos de corte de 21 a 42 dias, quando criados em alta temperatura cíclica (25,5 a 33,3\%).

Os níveis de lisina da ração influenciaram $(\mathrm{P}<0,07)$ o peso absoluto da sobrecoxa, que aumentou de forma quadrática até o nível de 1,02\%, segundo a equação $\hat{Y}=-713,3-1773,73$ lis $-866,164 \operatorname{lis}^{2}\left(r^{2}=0,63\right)$.

Os níveis de lisina na ração influenciaram $(\mathrm{P}<0,01)$ os pesos absoluto e relativo da gordura abdominal, que reduziram de forma quadrática até o nível de $1,00 \%$ de lisina, segundo as equações $\hat{Y}=-315,5-602,109$ lis $+301,385 \operatorname{lis}^{2}\left(\mathrm{r}^{2}=0,98\right)$ e $\hat{\mathrm{Y}}=25,6898$ e 49,1016 lis $+24,4444 \operatorname{lis}^{2}\left(\mathrm{r}^{2}=0,99\right)$. Mendes et al. (1997) também verificaram efeito dos níveis de lisina sobre o conteúdo de gordura abdominal expresso como porcentagem da carcaça de frangos de corte de 21 a 42 dias, criados em alta temperatura. No entanto, Barboza (1998) não constatou efeito dos níveis de 0,80 a $1,10 \%$ de lisina sobre a gordura abdominal em frangos de corte na fase de 22 a 40 dias, quando mantidos em ambiente termoneutro.

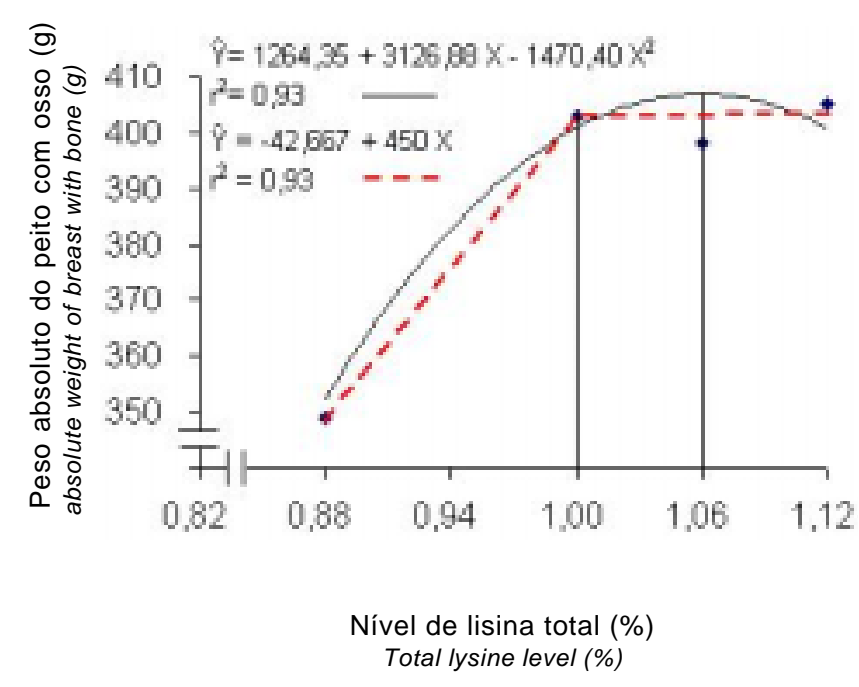

Figura 6 - Nível de lisina da ração e peso absoluto do peito com osso $(\mathrm{g})$ de frangos de corte aos 42 dias mantidos em ambiente de alta temperatura $\left(25,6^{\circ} \mathrm{C}\right)$.

Figure 6 - Dietary lysine level diet and absolute weight of breast with bone $(\mathrm{g})$ of broilers at 42 days of age, under high environmental temperature $\left(25.6^{\circ} \mathrm{C}\right)$.

\section{Conclusões}

Frangos de corte, no período de 22 a 42 dias de idade, submetidos à temperatura ambiente de $25,6^{\circ} \mathrm{C}$, exigem $1,05 \%$ de lisina total para máximo desempenho e deposição de proteína na carcaça.

\section{Literatura Citada}

AVIAN FARMS. Broiler manual International, 1998. 34p. (http:/ /www.avianfarms.com)

BAKER, D.H.; MOLITORIS, B.A. Partioning of nutrients for growth and other metabolic functions: efficiency and priority considerations. Poultry Science, v.70, p.1797-1805, 1991.

BARBOZA, W.A. Exigências nutricionais de lisina para duas marcas comerciais de frangos de corte. Viçosa, MG: Universidade Federal de Viçosa, 1998. 116p. Tese (Doutorado em Zootecnia) - Universidade Federal de Viçosa, 1998.

BAZIZ, H.A.; GERAERT, P.A.; GUILLAUMIN, S. Chronic heat exposure enhances fat deposition and modifies muscle and fat partition in broiler carcasses. Poultry Science, v.75, p.505-513, 1996.

BILGILI, S.F.; MORAN Jr., E.T.; ACAR, N. Strain cross response on heavy male broilers to dietary lysine in the finisher feed:live performance and further processing yields. Poultry Science, v.71, p.850-858, 1992.

BUFFINGTON, D.E.; COLAZZO-AROCHO, A.; CANTON, et al. Black globe-humidity index (BGHI) as confort equation for dairy cows. Transaction of the American Society of Agricultural Engineering, v.24, p.711-714, 1981.

CAHANER, A.; PINCHASOV, Y.; NIR, I. et al. Effects of dietary protein under high ambient temperature on body weight, breast, meat yield, and abdominal fat deposition of broiler stocks differing in growth rate and fatness. Poultry Science, v.74, p.968-975, 1995.

CAMPOS, E.J. Programa de alimentação e nutrição para as aves de acordo com o clima: reprodutoras. In: SIMPÓSIO INTERNACIONAL DE AMBIÊNCIA E INSTALAÇÃO NA AVICULTURA INDUSTRIAL, 1995, Campinas. Anais... Campinas: FACTA, 1995. p.251-258.

CONHALATO, G.S. Exigência de lisina digestível para frangos de corte machos. Viçosa, MG: Universidade Federal de Viçosa, 1998. 79 p. Dissertação (Mestrado em Zootecnia) - Universidade Federal de Viçosa, 1998.

DESCHEPPER, K.; DE GROOTE, G. Effect of dietary protein, essential and non-essential amino acids on the performance and carcass composition of male broiler chickens. British Poultry Science, v.36, p.229-245, 1995.

GOMES, P.C.; ALBINO, L.F.T.; SILVA, M.A. Criação de frangos de corte. Informe Técnico. Viçosa, MG. Ano 17, n.78. 1996. 18p.

HAN, Y.; BAKER, D.H. Digestible lysine requirement of male and female broiler chicks during the period three to six weeks posthatching. Poultry Science, v.73, p.1739-1745, 1994.

HICKLING, D.; GUENTER, W.; JACKSON, M.E. The effects of dietary lysine and methionine on broiler chicken performance and breast meat yield at different ages. Poultry Science, v.68, p.163-168 (Supl. 1), 1989.

HOLSHEIMER, J.P.; VEERKAMP, C.H. Effect of dietary energy and lysine content on performance and yields of two strains of males broiler chicks. Poultry Science, v.71, p.872-879, 1992. 
JACKSON, M.E.; LI, S.; DAY, E.J. et al. The effects of different lysine levels fed in constant proportions to different crude protein levels on the live performance and carcass characteristics of broiler chickens. Poultry Science, v.68, p.186 (Suppl.), 1989.

KIDD, M.T.; KERR, B.J.; ANTHONY, N.B. Dietary interactions between lysine and threonine in broilers. Poultry Science, v.76, p.608-614, 1997.

MENDES, A.A.; WATKINS, S.E.; ENGLAND, J.A. et al. Influence of dietary lysine level and arginine: lysine rations on performance of broilers exposit to heat or cold stress during the period of three to six weeks of age. Poultry Science, v.76, p.472-481, 1997.

MORAN JR., E.T.; BILGILI, S.F. Processing losses, carcass quality and meat yields for broiler chicken, receiving diets marginally deficient to adequate in lysine prior to marketing. Poultry Science, v.69, p.702-710, 1990.

OLIVEIRA, R.F.M.; DONZELE, J.L.; FREITAS, R.T.F. et al. Efeito da temperatura sobre o desempenho e sobre os parâmetros fisiológicos e hormonal de leitões consumindo dietas com diferentes níveis de energia digestível. Revista Brasileira de Zootecnia, v.26, p.1173-1182, 1977.

OLIVEIRA NETO, A.R. Efeito de níveis de energia da ração e da temperatura ambiente sobre o desempenho e parâmetros fisiológicos de frangos de corte. Viçosa, MG: Universidade Federal de Viçosa, 1999. 111p. Dissertação (Mestrado em Zootecnia) - Universidade Federal de Viçosa, 1999.

OLIVEIRA NETO, A.R.; OLIVEIRA, R.F.M.; DONZELE, J.L. et al.Efeito da temperatura ambiente sobre o desempenho, características de carcaça e peso de órgãos em frangos de corte. II - Alimentação controlada. In: REUNIÃO ANUAL BRASILEIRA DA SOCIEDADE BRASILEIRA DE ZOOTECNIA, 35., 1998, Botucatu. Anais... Botucatu: Sociedade Brasileira de Zootecnia, 1998. p.61-63.

RESENDE, J.A.A.; ROSTAGNO, H.S.; SILVA, M. et al. Níveis de proteína, aminoácidos sulfurosos e lisina em rações de frangos submetidos a regime de alta temperatura. Fase de crescimento. Revista Brasileira de Zootecnia, v.9, p.108-124, 1980.

RHODIMET nutrition guide 2.ed. France: Rhône-Ponlenc Animal Nutrition, 1993. 55p.

ROSTAGNO, H.S. Rações com diferentes níveis de proteína para frangos de corte. In: ENCONTRO DE NUTRIÇÃO ANIMAL, 3., 1997, São Paulo. Anais... São Paulo: Degussa, 1997. p.1-10.
ROSTAGNO, H.S.; BARBARINO Jr., P.; BARBOZA, W.A. Exigências nutricionais das aves determinadas no Brasil. In: SIMPÓSIO INTERNACIONAL SOBRE EXIGÊNCIAS NUTRICIONAIS DE AVES ESUÍNOS, 1996, Viçosa. Anais.. Viçosa, MG: Universidade Federal de Viçosa, 1996. p.361.

UNIVERSIDADE FEDERAL DE VIÇOSA - UFV. SAEG Sistema para Análises Estatísticas e Genéticas. Versão 7.1. Viçosa, MG: 1997. 150p. (Manual do usuário).

SCHEUERMANN, G.N.; MAIER, J.C.; BELLAVER, C. et al. Exigência de lisina para frangos de corte na fase de 21 a 42 dias de idade. In: REUNIÃO ANUAL DA SOCIEDADE BRASILEIRA DE ZOOTECNIA, 30., Rio de Janeiro. Anais... Rio de Janeiro: Sociedade Brasileira de Zootecnia, 1993. p.315-315.

SIBBALD, I.R.; WOLYNETZ, M.S. Effects of dietary lysine and feed intake on energy utilization and tissue synthesis by broiler chicks. Poultry Science, v.65, p.98-105, 1986.

SILVA, D.J. Análise de alimentos: métodos químicos e biológicos. Viçosa, MG: Universidade Federal de Viçosa, 1992. 166p.

SUMMERS, J.D.; SPRAT, D.; ATKINSON, J.L. Broiler weight gain and carcass composition when fed diets varying in amino acid balance, dietary energy, and protein levels. Poultry Science, v.71, p.263-273, 1992. 